\title{
Desenvolvimento Territorial Sustentável Iniciativa de Economia Social e Solidária no Contexto do Turismo
}

http://dx.doi.org/10.21527/2237-6453.2019.49.94-111

Recebido em: 23/8/2018

Aceito em: 4/6/2019

\section{Luciana Francisco de Abreu Ronconi ${ }^{1}$, Elaine Cristina de Oliveira Menezes ${ }^{2}$, Bernadete de Lourdes Bittencourt ${ }^{3}$}

\begin{abstract}
RESUMO
O presente trabalho buscou compreender de que maneira um empreendimento de economia social e solidária, situado na Comunidade da Costa da Lagoa, Florianópolis, Santa Catarina, Brasil, contribui para o fortalecimento tanto do turismo quanto da cultura local, rumo ao desenvolvimento territorial sustentável. As atividades que se referem ao turismo são, atualmente, as responsáveis pela economia do local, superando as tradicionais atividades relacionadas com à agricultura de subsistência e à pesca artesanal. Partindo-se de um referencial teórico sobre economia social e solidária e desenvolvimento territorial sustentável, a pesquisa qualitativa caracterizou-se como estudo de caso exploratório e descritivo e contou com entrevistas semiestruturadas junto aos representantes da cooperativa de barcos. O estudo constatou que a cooperativa tem sido um espaço de integração social, construção de identidade e cidadania. Os entrevistados, todavia, pontuam a carência de assessoria qualificada e de apoio técnico, assim como de investimentos de órgãos públicos e de organizações não governamentais para que haja maior incremento do turismo e desenvolvimento do território.
\end{abstract}

Palavras-chave: Desenvolvimento territorial sustentável. Economia social e solidária. Turismo.

\section{SUSTAINABLE TERRITORIAL DEVELOPMENT: AN INITIATIVE OF SOCIAL AND SOLIDARITY ECONOMY IN THE CONTEXT OF TOURISM}

\begin{abstract}
The present work seeked to understand how an enterprise of social and solidarity economy located in the Community of the Coast of Lagoa, Florianópolis, Santa Catarina, Brazil, contributes to the strengthening of both tourism and local culture towards sustainable territorial development. The tourism related activities are currently responsible for the local economy by overcoming the traditional activities related to subsistence farming and artisanal fisheries. Starting from a theoretical framework on social and solidarity economy and sustainable territorial development the qualitative research characterized as the exploratory and descriptive study of the case and had semi-structured interviews with representatives of boat cooperative. The study found that the cooperative has been an area of social integration, identity construction, and citizenship. However, respondents punctuate the lack of qualified advice and technical support, as well as public agencies for investments and non-governmental organizations for greater growth of tourism and development of the territory.
\end{abstract}

Keywords: Territorial development. Social and solidarity economy. Tourism.

\footnotetext{
${ }^{1}$ Doutora em Sociologia Política pela Universidade Federal de Santa Catarina (UFSC). Professora da Universidade do Estado de Santa Catarina (Udesc). lucianaronconi20@yahoo.com.br

${ }^{2}$ Doutora em Sociologia Política pela Universidade Federal de Santa Catarina (UFSC). Professora da Universidade Federal do Paraná (UFPR). eoliveira.menezes@gmail.com

${ }^{3}$ Doutora em Sociologia Econômica e das Organizações pela Universidade de Lisboa (UL-PT). Professora da Universidade de Aveiro (UA-PT). bernadete@ua.pt
} 
Nas últimas décadas as organizações de economia social e solidária têm desempenhado papel fundamental no desenvolvimento territorial sustentável das economias emergentes. Para além de criar oportunidades de emprego para grupos vulneráveis, tais organizações frequentemente impulsionam projetos duradouros, proporcionando uma série de serviços que, normalmente, deveriam ter sido oferecidos pelo governo (CARY; LAVILLE, 2015). Embora a economia social e solidária tenha recebido cada vez mais atenção na literatura, o impacto desse setor específico para o desenvolvimento do turismo não foi profundamente pesquisado, permanecendo amplamente desconhecido (IORGULESCU; RĂVAR, 2015).

Parte-se do princípio de que a economia social e solidária se refere a um tipo específico de fazer negócios de maneira sustentável, em que os resultados de suas atividades tendem a promover a sustentabilidade econômica, social, cultural e ecológica, sobrelevando, na comunidade, os recursos sociais e naturais (BITTENCOURT, 2014; RONCONI, 2012). Alguns autores afirmam que a atenção dada à economia social e solidária tem crescido e que esse tipo de empreendimento econômico apoia diretamente um desenvolvimento mais sustentável do mercado de trabalho (LAVILLE, 2015; LAVILLE; YOUNG; EYNAUD, 2015). Partindo desta base, questiona-se se as organizações de economia social e solidária têm influenciado positivamente o desenvolvimento territorial sustentável no quadro do turismo local (UNWTO, 2017).

O potencial do turismo, como uma atividade econômica, tem sido considerado uma força motriz no desenvolvimento de territórios, especialmente aqueles que possuem riquezas naturais e/ou culturais (GUILLAUMON, 2012; UNWTO, 2017). A Costa da Lagoa é um destino turístico com área geográfica definida que, além de preservar as tradições da cultura açoriana, é considerado, por suas belas paisagens, um dos principais atrativos turísticos da cidade. A comunidade oferece um conjunto de produtos e serviços turísticos integrados (transporte, alimentação, artesanato) que são comercializados e consumidos pelos turistas. Assim, o conceito de destino turístico, desenvolvido por Buhalis (2000), é claramente evidenciado na realidade estudada.

A Lei $n$ o 11.771, de 17 de setembro de 2008 (Lei do Turismo), principal marco legal do turismo no país, pontua que as atividades turísticas devem ser desenvolvidas de forma sustentável e que as comunidades e territórios devem ser incluídos nos processos de produção e consumo do turismo (MTUR, 2018). O Ministério do Turismo do Brasil (MTur), ao formular o Plano Nacional de Turismo 2018/2022, além de apresentar as contribuições do setor para o desenvolvimento econômico, social e a erradicação da pobreza, definiu as diretrizes que devem nortear o desenvolvimento do turismo brasileiro, como a participação e diálogo com a sociedade, a geração de oportunidades de emprego e empreendedorismo, o incentivo à inovação e ao conhecimento e a regionalização como abordagem territorial e institucional para o planejamento (MTUR, 2018).

É necessário que diferentes setores compreendam a importância do turismo para o desenvolvimento da comunidade da Costa da Lagoa e da cidade de Florianópolis, pois é a partir de um desenvolvimento interorganizacional que projetos e ações ganharão sustentabilidade e possibilitarão o desenvolvimento e o crescimento da economia local e regional (ANDRIGHI; HOFFMANN, 2010). 
O presente artigo parte dos conceitos de Desenvolvimento Territorial Sustentável (DTS) e economia social e solidária. O DTS é um conceito em construção que se fundamenta nos trabalhos de Sachs (1986) sobre o ecodesenvolvimento, incluindo, nesse estudo, a gestão racional do ambiente. Também inclui os trabalhos acerca da abordagem do desenvolvimento territorial, com foco no conceito de território (território dado e construído) e na distribuição de atividades produtivas locais (PECQUEUR, 2009; COURLET, 2006; CARRIÈRE; CAZELLA, 2006). Na concepção destes autores, a prática coerente ao DTS fomenta a formação de redes locais com o objetivo de valorizar os recursos do território, sobretudo a gestão sustentável dos recursos naturais, privilegiando o desenvolvimento territorial. Tanto estudos destes autores quanto estudos mais recentes (MENEZES; RONCONI; SERVA, 2016; VIEIRA, 2013), consideram que as estratégias propostas pelo DTS são condições e um outro modo de sobrevivência das comunidades tradicionais que se encontram à margem do modelo de produção mundial. Nesta linha de raciocínio, o ponto de partida para a definição dos fundamentos do DTS foca a degradação socioambiental e sua relação com estratégias de desenvolvimento de longo prazo. É a partir deste foco que o trabalho dos pescadores e das comunidades tradicionais torna-se decisivo no atual contexto, pois suas atividades incorporam-se perfeitamente aos recursos naturais.

No debate sobre o impacto do turismo para o DTS, observam-se poucos estudos que apontam o relevante papel que as experiências de economia social e solidária possam ter no desenvolvimento do turismo e das comunidades locais. Um dos principais impulsionadores dessa crescente atenção é o fato de que a economia social consegue integrar diferentes grupos de pessoas em um mercado de trabalho cada vez mais competitivo (CARY; LAVILLE, 2015; LAVILLE, 2015).

Embora a literatura aponte a grande diversidade de termos utilizados para designar o campo da economia social, do terceiro setor, da economia solidária ou do setor não lucrativo (BITTENCOURT, 2014), o termo economia solidária foi assumido pelo Estado brasileiro (RONCONI, 2008, 2012). No Brasil, no período de 2003-2016, a economia solidária esteve inserida no Ministério do Trabalho e Previdência Social (MTPS). Seguindo os princípios de Paul Singer (1932-2018), trata das cooperativas, associações, empresas autogestionadas, grupos solidários, redes solidárias e clubes de troca, a partir da ideia de empreendimentos econômicos solidários (SENAES, 2007). Segundo Singer (2002), o termo economia solidária é um movimento mundial que diz respeito à produção, consumo e distribuição de riqueza com foco na valorização do ser humano. Tem como base os empreendimentos coletivos, que "são organizações, singulares ou complexas, de caráter coletivo, onde trabalhadores e/ou trabalhadoras do meio urbano ou rural exercem a gestão coletiva de seus empreendimentos" (SINGER, 2002, p. 215).

A antiga Senaes (extinta no ano de 2016), em seus documentos oficiais, define a economia solidária como "o conjunto de atividades econômicas - de produção, distribuição, consumo, poupança e crédito - organizadas sob a forma de autogestão, i.e., pela propriedade coletiva do capital e participação democrática [...] nas decisões dos membros da entidade promotora da atividade" (2007, p. 7). Nesse conjunto de atividades e formas de organização, destacam-se quatro importantes características: cooperação, autogestão, viabilidade econômica e solidariedade. 
Comparando as definições de economia social e solidária, observa-se que o significado anotado pela Social Economy Europe (2017) destaca que a economia social inclui organizações como cooperativas, mutualidades, associações e fundações de todos os setores sociais e econômicos, caracterizadas por objetivos sociais específicos e uma forma distintiva de empreendedorismo. Neste contexto, as expressões economia solidária e economia social designam, de acordo com o nosso entendimento, o conjunto de organizações que, a partir de atividades de suporte social e/ou econômicas, produzem bens e serviços de forma autônoma, tendo por princípio a solidariedade social, o poder compartilhado e a natureza democrática das tomadas de decisão (RONCONI, 2012).

A presente pesquisa desenvolveu-se a partir da compreensão de que a economia social e a economia solidária giram em torno da ideia de solidariedade e têm sido consideradas relevantes do ponto de vista econômico, social, político e cultural. No Brasil, todavia, pode-se considerar que o processo de compreensão do fenômeno economia social e economia solidária em relação a outros países, por exemplo Portugal (BITTENCOURT; RONCONI, 2016), apresenta algumas lacunas tanto legais quanto de práticas de adoção reconhecidas. A partir destas considerações, o objetivo desta pesquisa consiste em compreender de que maneira um empreendimento de economia social e solidária, situado na Comunidade da Costa da Lagoa, Florianópolis, Santa Catarina, Brasil, contribui para o fortalecimento tanto do turismo quanto da cultura local, rumo ao desenvolvimento territorial sustentável.

Inicialmente expomos os procedimentos metodológicos que nortearam a pesquisa. Na sequência resgatamos os principais conceitos e abordagens acerca da economia social e solidária e o desenvolvimento territorial sustentável. Em seguida apresentamos o território pesquisado e o caso da Cooperativa de Barcos de Florianópolis - Cooperativa Alfa. Por fim, apresentamos as nossas considerações e sugestões para estudos futuros, e as referências bibliográficas empregadas na pesquisa.

\section{PROCEDIMENTOS METODOLÓGICOS}

No que se refere aos aspectos metodológicos, a pesquisa é de natureza qualitativa, e teve caráter exploratório e descritivo (MINAYO, 1994; RICHARDSON et al., 1985; TRIVIÑOS, 1987). O levantamento de informações incluiu fontes de dados primários e secundários. Os dados primários foram obtidos na pesquisa de campo por meio da aplicação de entrevistas semiestruturadas. Além disso, realizou-se pesquisas e visitas informais na comunidade da Costa da Lagoa. Os dados secundários foram obtidos pela pesquisa documental e por dados levantados em periódicos, revistas, jornais e demais publicações que circulam na mídia.

A seleção da região estudada deu-se em virtude de o litoral catarinense ter uma forte atividade turística e pesqueira, assim como potencial para inovações no campo da economia social e solidária. Especificamente, a Costa da Lagoa (Figura 1) é um local de intenso turismo incrementado pela ação das cooperativas de barco, que realizam tanto o transporte de moradores quanto de turistas interessados em usufruir dos recursos naturais locais. 


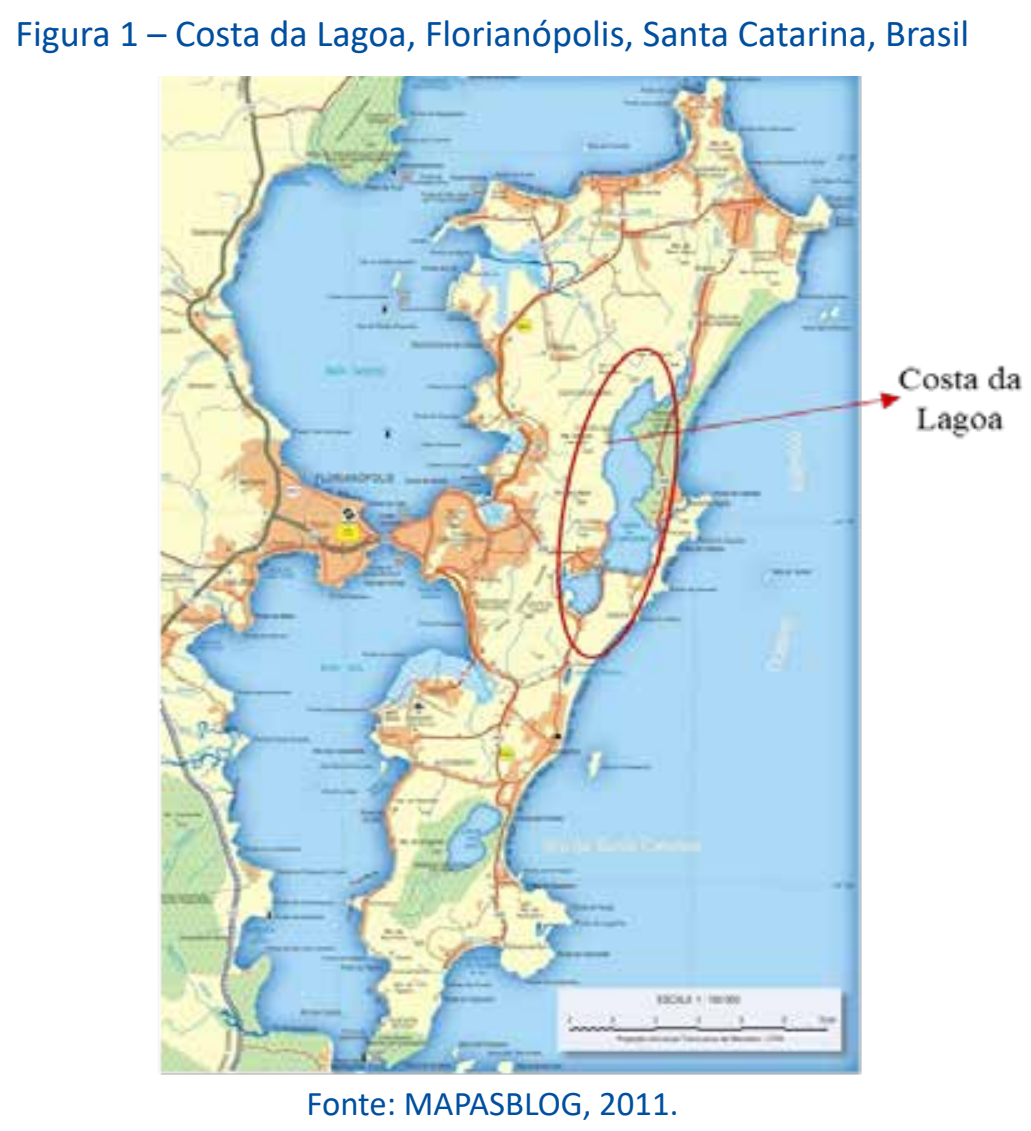

Para fins desta pesquisa, a cooperativa de barcos estudada será denominada ficticiamente como Cooperativa Alfa. Quanto aos sujeitos de pesquisa, foram selecionados seis representantes da Comunidade da Costa da Lagoa que tinham relação com a atividade do turismo, da pesca e atores-chave da Cooperativa Alfa, sendo eles: representantes dos pescadores da Comunidade da Costa da Lagoa, representantes da cooperativa de barcos - Cooperativa Alfa, formada por pescadores cooperados - e representantes da associação comunitária local, totalizando seis entrevistados.

Os critérios de seleção dos entrevistados deram-se em razão do acesso facilitado e da indicação por parte de atores-chave como: representante da Empresa de Pesquisa Agropecuária e Extensão Rural de Santa Catarina - Epagri - e da própria cooperativa de barcos. A entrevista semiestruturada, considerada um instrumento importante de coleta de dados, foi realizada junto a esses representantes da comunidade e centrou-se em compreender as atividades realizadas pela cooperativa. Assim, buscou entender: i) a maneira pela qual os cooperados realizam tanto a divisão do seu trabalho quanto do rendimento do seu trabalho; ii) o apoio das instituições públicas e privadas para a cooperativa de barcos e para o incremento do turismo; iii) o envolvimento dos pescadores em ações conjuntas e a relação da comunidade com a atividade da pesca e do turismo.

A análise qualitativa do conteúdo pesquisado foi feita a partir de reflexões sobre o objeto analisado (organização de economia social e solidária), leituras de teóricos pertinentes, entrevistas semiestruturadas e análise documental. A matriz teórico-metodológica do estudo resgata os conceitos de economia social e solidária e turismo, na perspectiva do desenvolvimento territorial sustentável, conforme ilustrado no Quadro 1 a seguir. 
Quadro 1 - Matriz teórico-metodológica

\begin{tabular}{|l|l|l|l|}
\hline \multirow{4}{*}{ D } & \multicolumn{1}{|c|}{ Conceitos } & \multicolumn{1}{|c|}{ Elementos } & \multicolumn{1}{c|}{ Coleta e análise } \\
\cline { 2 - 4 } T & Economia social e solidária & $\begin{array}{l}\text { Sustentabilidade Econômica } \\
\text { Sustentabilidade Social }\end{array}$ & $\begin{array}{l}\text { Entrevistas semiestru- } \\
\text { turadas e observação }\end{array}$ \\
\cline { 2 - 5 } S & Turismo & $\begin{array}{l}\text { Sustentabilidade Cultural } \\
\text { Sustentabilidade Ecológica }\end{array}$ & $\begin{array}{l}\text { Entrevistas semiestru- } \\
\text { turadas e observação }\end{array}$ \\
\hline
\end{tabular}

Fonte: Elaborado pelos autores.

Os dados coletados e os resultados obtidos serão apresentados na forma descritiva/interpretativa, por meio das informações sistematizadas e interpretadas à luz dos conhecimentos teóricos categorizados conforme a técnica de análise de conteúdo, tendo como suporte os conceitos-chave e seus elementos mencionados anteriormente.

\section{A CONTRIBUIÇÃO DA ECONOMIA SOCIAL E SOLIDÁRIA PARA O TURISMO E O DESENVOLVIMENTO TERRITORIAL SUSTENTÁVEL}

No âmbito da revisão de literatura, os conceitos norteadores foram o desenvolvimento territorial sustentável e a economia social e solidária. O DTS é concebido como um enfoque de planejamento e gestão, tendo como ponto de partida a problemática da degradação socioambiental e sua relação com estratégias de desenvolvimento de longo prazo (SACHS, 1986, 1993, 2007; VIEIRA, 2006, 2013, 2016). É preciso destacar duas vertentes importantes para a definição do conceito de DTS.

Primeiramente apresentamos a contribuição dos estudos de Bagnasco (1999), Becattini (1999), Benko (2001), Courlet e Soulage (1994), Courlet $(2001,2006)$ e de Pecqueur $(2006,2009)$ sobre o desenvolvimento territorial e a importância dos territórios no âmbito da inovação. Estes autores trazem resultados de pesquisas no campo socioeconômico a partir de experiências que mostram e definem conceitos como: distritos industriais, sistemas produtivos locais, clusters, ambiente inovador, arranjos produtivos locais. Tais experiências, a partir de suas especificidades, revelaram novos elementos no fortalecimento das dinâmicas produtivas do território, além de contribuírem para a gestão organizacional das empresas ali instaladas. Assim, esses novos elementos configuram-se como i) a cultura que identifica e personaliza o território; ii) o capital social caracterizado pela sinergia, cooperação e competição; iii) o capital humano relativo à qualidade e acesso à mão de obra e conhecimento acumulado; iv) a logística na difusão de inovação; v) a possibilidade de regulação setorial conjunta (BAGNASCO, 1999; BECATTINI, 1999; BENKO, 2001; COURLET; SOULAGE, 1994; COURLET, 2001).

A segunda vertente refere-se às contribuições de Vieira $(2016,2006)$ e Sachs (2007) e seus estudos sobre sustentabilidade, resgatando importantes elementos para a gestão das organizações na atualidade. Para estes autores, tais elementos fundamentam-se nos pilares do desenvolvimento sustentável, como i) prudência ecológica, ii) satisfação das necessidades básicas e promoção da equidade, e iii) autonomia e redefinição do conceito de eficiência econômica, que alia a produtividade com a minimização das perdas e reaproveitamento dos resíduos e dejetos como insumos para o sistema produtivo. 
Assim, para esta proposta de pesquisa recuperamos a concepção de DTS pautada nos postulados do ecodesenvolvimento, da gestão racional do ambiente e do desenvolvimento territorial (SACHS, 1986; PECQUEUR, 2009; VIEIRA, 2006, 2016). Essa concepção de desenvolvimento valoriza a formação de redes locais, os recursos regionais e a gestão dos recursos naturais de forma a privilegiar o desenvolvimento local (MENEZES, 2011).

Sachs (1993) distingue cinco dimensões do conceito ecodesenvolvimento. A primeira é a sustentabilidade social, relacionada à construção de uma nova civilização do ser, em contraposição à civilização do ter. A segunda é a sustentabilidade econômica, "possibilitada por uma alocação e gestão mais eficiente dos recursos e por um fluxo regular do investimento público e privado. [...] a eficiência econômica deve ser avaliada mais em termos macrossociais do que apenas por meio de critérios de lucratividade microempresarial" (SACHS, 1993, p. 27). Segue com a sustentabilidade ecológica, a ser alcançada por meio da habilidade na utilização da base de recursos potenciais existente nos diversos ecossistemas, da limitação do consumo de recursos não renováveis e produtos facilmente esgotáveis e sua substituição por recursos renováveis. Esta terceira dimensão ainda envolve a redução da poluição mediante a reciclagem sistemática de dejetos das atividades produtivas e de consumo. Além disso, o combate ao consumo supérfluo de mercadorias, a pesquisa de tecnologias limpas e, por fim, definir regras para proteção ambiental, bem como de um aparato institucional que assegure o cumprimento das normas propostas. A quarta dimensão é a sustentabilidade espacial, no sentido do aperfeiçoamento progressivo das configurações rurais-urbanas. Por último, a sustentabilidade cultural, relacionada à "[...] busca das raízes endógenas dos modelos de modernização e dos sistemas rurais integrados de produção, privilegiando processos de mudança no seio da continuidade cultural e traduzindo o conceito normativo de ecodesenvolvimento em uma pluralidade de soluções particulares, que respeitam as especificidades de cada ecossistema, de cada cultura e de cada local" (SACHS, 1993, p. 27).

O critério de sustentabilidade ampliada articula as dimensões socioeconômica, sociocultural, sociopolítica e socioecológica e tende a se impor como um fator determinante no desenho de estratégias alternativas de desenvolvimento rural e urbano (MENEZES; VIEIRA, 2011). Para Bittencourt (2014), a concepção de desenvolvimento territorial denota iniciativas de base local. Essa mobilização natural do tecido social indica que a sociedade tem condições de conceber o seu próprio projeto de desenvolvimento em um dado território. Nesse contexto, a comunidade mobiliza-se em resposta às necessidades do lugar e atua em modelo de gestão democrática e coletiva para a utilização dos recursos e da capacidade do tecido societal, comprometidas com o DTS. Por conseguinte, a sociedade movimenta-se em processo democrático por meio de manifestação associativista e/ou cooperativa, conjugando os vários componentes ecossocioeconômicos do território (BITTENCOURT, 2014). Diante de tal argumento, verifica-se a importância da economia social e solidária para o turismo e o desenvolvimento territorial sustentável.

No contexto brasileiro a economia solidária refere-se às organizações de geração de trabalho e renda que colocam ênfase nos ideais do cooperativismo e nos princípios de autogestão e cooperação no trabalho, participação, igualitarismo e desenvolvimento 
humano. A economia solidária, a partir da concepção de Singer (2002) e no entendimento de Ronconi (2003), é compreendida como a forma de organizar a produção e/ou a distribuição que adota o princípio da democracia nas tomadas de decisão e da equanimidade (justiça) na distribuição dos resultados.

No Brasil, as primeiras iniciativas de políticas públicas voltadas para a economia solidária datam dos anos 90, e tiveram como principal referência a política desenvolvida pelo Partido Político - Partido dos Trabalhadores - na primeira gestão (1989/1992) da Prefeitura de Porto Alegre/RS. Posteriormente, outras administrações municipais investiram na economia solidária como política de geração de trabalho, renda e inclusão social. A partir dos anos 2000 , as experiências de cooperativas estenderam-se por todas as regiões brasileiras. Inicialmente, como alternativa ao desemprego e manutenção de postos de trabalho em empresas falidas, a multiplicação dessas experiências permite "que se fale na constituição de um sistema alternativo de produção ou, até mesmo, de um novo modo de produção baseado no cooperativismo e na solidariedade" (FARIA, 2005 , p. 12). Trata-se não apenas de uma alternativa econômica diante da crise do trabalho, mas de uma alternativa social no que se refere às múltiplas dimensões da vida, por exemplo valores, cultura, sociabilidade e comunicação, etc. (RONCONI, 2003).

$\mathrm{Na}$ economia solidária os valores de solidariedade, democracia, autogestão e autonomia devem se sobrepor aos valores do capital; devem coexistir com o mercado capitalista e, ao mesmo tempo, criticá-lo (SINGER, 2000). No Brasil, as organizações de economia solidária, de maneira geral, buscam resgatar os valores de solidariedade, democracia, autogestão e autonomia. Distinguem-se, de acordo com Singer (2002), por duas especificidades: estimulam a solidariedade entre seus membros mediante a autogestão e praticam a solidariedade para com a população trabalhadora em geral, com ênfase na ajuda aos mais desfavorecidos.

Algumas características interessantes do cooperativismo, segundo Irion (1997), são: que ele, o cooperativismo, tem por base a posse privada dos meios de produção, possuindo gestão e planejamento descentralizados e individualizados, centrados na cooperativa e no cooperado. Esse é um empreendimento com duas faces: uma econômica, quando atua como empresa e trata da realização e controle da economia dos cooperados; e outra social, quando promove condições voltadas ao meio social dos cooperados. É, portanto, "[...] uma associação autônoma de pessoas que se uniram voluntariamente para fazer frente às necessidades e aspirações econômicas, sociais e culturais comuns por meio de uma empresa de propriedade conjunta e democraticamente controlada" (IRION, 1997, p. 47).

Embora no Brasil utilize-se a expressão economia solidária, considera-se relevante destacar que noutros lugares do mundo, como no contexto da União Europeia, a expressão economia social tem sido utilizada largamente. Ela tem sido reconhecida, particularmente em Portugal, tanto pelas administrações públicas quanto pelo mundo acadêmico e pelo próprio setor da economia social (BITTENCOURT; RONCONI, 2016). A economia social, todavia, pode ser considerada a partir de diferentes vertentes. Simaens (2007) e Bittencourt (2014) reforçam a existência de três perspectivas: a francófona, a anglófona e a da União Europeia. Na perspectiva francófona utiliza-se mais a designação Economia Social, e tem predomínio na França, Bélgica, Quebec, Portugal, Espanha, Itália e Suécia. 
Na perspectiva anglófona predomina a designação Sociedade Civil e non-profit, enquanto na União Europeia o terceiro setor tem sido a expressão mais utilizada, apesar do progressivo reconhecimento do termo economia social.

O conceito de economia social tem sido desenvolvido, ainda, no âmbito do Centro Internacional de Pesquisa e Informação sobre Economia Pública, Social e Cooperativa (Ciriec) e progressivamente reconhecido pela União Europeia que adota uma definição abrangente, tendo em conta os critérios compreendidos na Carta de Princípios da Economia Social determinada pela Conferência Europeia Permanente das Cooperativas, Associações e Fundações (CEP-CMAF) (RONCONI; FERREIRA, 2014).

A Aliança Cooperativa Internacional $(\mathrm{ACl})$ define que cooperativa é uma associação autônoma de pessoas que, por meio de uma empresa de propriedade comum e democraticamente gerida, se unem de maneira voluntária com o objetivo de satisfazer aspirações e necessidades econômicas, sociais e culturais. Em 1995, a ACl estabeleceu os princípios que regem o funcionamento de toda e qualquer cooperativa no mundo: 1) associação voluntária e aberta; 2) controle democrático dos membros; 3) participação econômica dos membros; 4) autonomia e independência; 5) educação, treinamento e informação; 6) cooperação entre cooperativas; e 7) preocupação com a comunidade.

A economia social tem os princípios pontuados na Carta de Princípios da Economia Social, estabelecida pela Conferência Europeia Permanente das Cooperativas, Mutualidades, Associações e Fundações (CEP-CMAF), que são: primazia do indivíduo e do objeto social sobre o capital; adesão livre e voluntária; controle democrático pelos seus filiados (exceto as fundações que não possuem membros associados); conjugação dos interesses dos filiados/usuários e/ou do interesse geral; defesa e aplicação dos princípios de solidariedade e responsabilidade; autonomia de gestão e independência em relação aos poderes públicos; e a maior parte dos excedentes destina-se à consecução de objetivos em favor do desenvolvimento sustentável e da prestação de serviços de interesse para os associados e/ou do interesse geral (CESE, 2007).

O trabalho cooperativo tem sido apontado, principalmente nos países onde a economia social apresenta uma maior aceitação e goza de maior reconhecimento, como uma das saídas à crise do emprego na economia formal no mundo contemporâneo. Essa nova economia - a social -, baseada em redes de solidariedade, pode estimular a criação de empregos, melhorar as condições de empregabilidade e promover uma cultura de participação cívica. Sob esses aspectos, as organizações de economia social e solidária podem ser um espaço de inclusão e de resistência para uma parcela da população excluída do mercado de trabalho. Um espaço onde a dimensão humana não aparece de forma banalizada; onde o homem pode, por meio de um processo emancipatório, reconhecer a possibilidade de construir a história e intervir em seu contexto (RONCONI, 2008). Assim, como destaca Namorado (2009, p. 96), "as necessidades ou aspirações que as cooperativas visam satisfazer não são apenas de natureza econômica, mas também de natureza social e cultural".

Embora os empreendimentos de economia solidária e social enfrentem dificuldades de se sustentarem ao longo do tempo eles, têm sido uma alternativa para a geração de trabalho e renda, contribuindo para um novo modelo de desenvolvimento, mais integrado ao território e mais sustentável do ponto de vista socioambiental. Assim, verificamos que a economia social e solidária e o DTS são regidos por princípios que se 
complementam. Vemos na economia social e solidária a proposta de se criar um sistema social que garanta trabalho, renda, segurança social e educação para toda a população, preservando o ambiente, as características locais e difundindo a ideia de um desenvolvimento territorial integrado e sustentável, no qual impere a solidariedade e a justiça social. A partir desses princípios, conforme afirma Sachs (2007), criam-se possibilidades para que haja a ascensão de estratégias que acarretem a veiculação desse novo modelo de desenvolvimento. No caso estudado, pode-se observar a importância da economia social e solidária a partir das ações da cooperativa de barcos da Costa da Lagoa, para o DTS e para o incremento do turismo na região.

O campo de estudo encontra-se na região Sul do Brasil, no Estado de Santa Catarina, cidade de Florianópolis. Esta cidade possui, conforme estimativa do IBGE (2015), mais de 469 mil habitantes e tem como principais atividades econômicas o turismo, o comércio, a pesca e a maricultura, contando, também, com um crescente e importante polo tecnológico. O turismo é o setor que apresenta o maior crescimento, sendo um componente importante da economia global. É avaliado tanto pelo número de deslocamentos internacionais e domésticos quanto, sobretudo, pela criação de empregos onde quer que se desenvolva as suas atividades. É uma importante força motriz para o crescimento e desenvolvimento do território, podendo ser avaliado pelo volume de investimentos público e privado (MTUR, 2016). Apesar do turismo, em determinadas regiões tem repercussões negativas sobre a sociedade e o meio ambiente, e o seu papel como vetor de desenvolvimento tem sido reestruturado pela conscientização ambiental. Sendo, portanto, o ecoturismo um modo de turismo responsável às áreas naturais, e tendo por princípio a conservação do meio ambiente e o compromisso com o bem-estar da população local, pode ser considerado um veículo eficaz para capacitar as comunidades locais ao redor do mundo no combate à pobreza e para alcançar o DTS.

Mundialmente o ecoturismo ganha notoriedade com taxas entre $15 \%$ e $25 \%$ ao ano, segundo dados da Organização Mundial do Turismo, divulgados pelo Ministério do Turismo do Brasil (MTUR), em 2016. No Brasil é um dos segmentos que mais cresce. 0 país possui uma variedade de biomas, e muitas regiões contemplam o turismo ecológico e de aventura para os turistas nacionais e internacionais (MTUR, 2018). Os dados do MTUR (2018) mostram que, atualmente, há uma maior busca por atividades junto a natureza.

Desde a década de 90 Florianópolis apresenta uma crescente procura por atividades de ecoturismo, segundo dados relatados pelo Instituto Brasileiro do Turismo (Embratur), que identificou, em Santa Catarina, três polos de ecoturismo: Alto Vale do Itajaí, Planalto Serrano e Ilha de Santa Catarina (MTUR, 2016, 2018). De acordo com o plano turístico da ilha de Santa Catarina, a trilha da Costa da Lagoa é um dos atrativos mais procurados pela demanda oriunda do Centro de Atendimento ao Turista (CAT). Diante disso, a Costa da Lagoa conseguiu ampliar o seu patrimônio náutico, adaptando-se às novas condições de vida com uma atividade que emprega mais de uma centena de moradores por meio do transporte de passageiros. Para isso, reestruturou suas embarcações para atender não somente o transporte dos moradores, mas o fluxo demandado pelo turismo, conseguindo promover a continuidade do seu processo cultural náutico. 


\section{A Comunidade da Costa da Lagoa}

A Costa da Lagoa, considerada um ponto turístico emblemático da cidade de Florianópolis, capital do Estado de Santa Catarina, encontra-se na parte noroeste da Lagoa da Conceição. Sua população está distribuída em terrenos dispostos ao longo das margens dessa lagoa, sendo a área total ocupada de, aproximadamente, 9,77 km².

A comunidade, inicialmente povoada por imigrantes portugueses, oriundos dos Açores, desenvolvia atividades econômicas ligadas à agricultura de subsistência e pesca artesanal. Em razão da crise da pesca artesanal na região, todavia, as atividades relacionadas ao turismo são, atualmente, as responsáveis pela economia local. Os moradores possuem restaurantes especializados em frutos do mar e barcos que realizam o transporte de turistas até a comunidade. Neste contexto, os estudos de Tenório et al. (2018, p. 430) revelam uma análise que extrapola o meandro econômico, sublinhando "a importância da participação da comunidade no desenvolvimento de atividades turísticas, bem como a presença de elementos da cultura local, para que o turismo possa levar a um desenvolvimento mais amplo".

O acesso à Costa da Lagoa é efetuado apenas por trilhas em meio à Mata Atlântica (com duração média de duas horas de caminhada) ou com o transporte lacustre, realizado por duas cooperativas de barcos pertencentes aos próprios moradores da comunidade (com duração média de 20 minutos).

A Costa da Lagoa é integrada por cinco vilas que se estendem por todo o território, e possui, segundo informações do posto de saúde da comunidade, 267 residências. Conta com os serviços públicos de educação infantil, energia elétrica, telefonia, assistência médica (fornecida pelo posto de saúde local) e saneamento básico (somente para as regiões com maior concentração de restaurantes). Outros serviços disponibilizados na comunidade são os fornecidos pela Associação de Moradores da Costa da Lagoa (Amocosta), pela Associação de Bares e Restaurantes da Costa da Lagoa ( $A B R C L$ ) e pelas cooperativas de barcos.

O desenvolvimento econômico da comunidade, principalmente das vilas onde concentram-se a maior parte dos restaurantes, é dinamizado pela cooperativa de barcos, que, além do transporte dos moradores locais, possibilita a mobilidade para turistas. O transporte hidroviário é, assim, o acesso mais usual à Costa da Lagoa. Há também as vias das trilhas que são uma alternativa turística aos que procuram contato com a natureza em busca de turismo ecológico. O turismo cria oportunidades de desenvolvimento para os restaurantes, os artesãos e as rendeiras locais. Observa-se que, conforme destacam Fagundes e Zorzella (2012), as dinâmicas de desenvolvimento, quando idealizadas de modo sustentáveis, sobressaem os saberes locais, fomentam o conhecimento e a cultura e interligam as comunidades e a natureza.

A Costa da Lagoa é um dos poucos lugares do litoral brasileiro que ampliou sua condição náutica - no número de embarcações e de pessoas que a desenvolvem - para o transporte aquaviário - em decorrência da falta de acesso rodoviário à comunidade (DA LUZ; MARTINS, 2014). A partir desse modelo de transporte, as atividades desenvolvidas em práticas conjuntas aumentaram os vínculos entre os pescadores, fortalecendo a conscientização da importância da preservação das trilhas e do meio ambiente para o ecossistema que habita a Costa da Lagoa. 


\section{O Caso da Cooperativa de Barcos de Florianópolis - Cooperativa Alfa}

No caso analisado, a Cooperativa de Barcos, fundada em 1995 por moradores do Bairro Costa da Lagoa, tem como objetivo fazer o transporte de passageiros e turistas no trajeto Lagoa-Costa-Lagoa. Anteriormente à formação da cooperativa, a Prefeitura detinha o transporte de passageiros da Costa da Lagoa, que acabou por deixar de o fazer dada as dificuldades em manter a qualidade dos barcos. Ainda no tempo em que a Prefeitura detinha o serviço, alguns pescadores, individualmente, em seus próprios barcos, realizavam o transporte apenas em alguns horários e em situações de muito movimento, como as de temporada em que a demanda (transporte dos turistas) não era absorvida pela Prefeitura.

A partir do momento que a Prefeitura deixou de fazer o transporte, todas as linhas ficaram para a cooperativa, que acabou por atender as linhas que não eram absorvidas pelas instituições convencionais, incluindo-se o Estado e o mercado (CARY; LAVILLE, 2015). O trabalho, que era realizado individualmente e com muitos conflitos interpessoais, foi regulamentado por meio de estatuto interno da cooperativa.

No que se refere à sustentabilidade econômica, levando-se em conta o referencial teórico utilizado neste estudo, a cooperativa de barcos de Florianópolis é considerada uma organização de economia solidária. Ela tem o objetivo da produção de bens e/ou prestação de serviços, e aplica o princípio da democracia nas tomadas de decisão e a equanimidade na distribuição dos resultados produzidos ou distribuídos.

Ainda na discussão relativa à sustentabilidade econômica, sustentabilidade social e cultural, a cooperativa contava, em 2010, com 30 cooperados que residem na Costa da Lagoa e possuem a habilidade da pesca ou de manuseio com barco. Além do transporte de passageiros, a cooperativa realiza, esporadicamente e com agendamento prévio, passeios turísticos para o oceano (Ilha do Campeche); esses passeios ocorrem especialmente no período de férias e correspondem a um aumento de trabalho e receita para os cooperados. Neste contexto, o nosso objeto de estudo - a cooperativa - apresenta o que Sachs (1993, p. 27) destaca que é a possibilidade de uma "[...] alocação e gestão mais eficiente dos recursos e por um fluxo regular do investimento público e privado. [...] a eficiência econômica deve ser avaliada mais em termos macrossociais do que apenas por meio de critérios de lucratividade microempresarial".

Para ser membro da cooperativa é necessário, de acordo com os entrevistados, ser morador da Costa da Lagoa, barqueiro e pescador. Além desses pré-requisitos, a entrada de novos membros na cooperativa se dá mediante a aprovação de todos os cooperados e a compra de cotas por parte do interessado. Grande parte das pessoas que trabalham na cooperativa são cooperados. A exceção fica por conta de um funcionário, um cobrador de passagem e uma funcionária para a limpeza, que recebem salário.

Os membros da cooperativa, em sua maioria, possuem laços de parentesco, o que, segundo Granovetter $(1973,2000)$, é caracterizado como laços fortes. Essa característica do grupo dificulta a administração da cooperativa, posto que, quando ocorre algum problema, a punição e a obediência do regulamento interno, em alguns casos, tornam-se difíceis. Como, porém, demonstra pesquisa realizada na Costa da Lagoa por Serafim et al. (2012), a relação de parentesco propicia formas de solidariedade que beneficiam não somente determinados grupos, mas todos os membros da comunidade. 
No âmbito da sustentabilidade social e cultural, em razão do próprio serviço que executa e à exigência de o cooperado ser pescador e barqueiro, a cooperativa é formada majoritariamente por homens. Quanto à escolaridade, o presidente informa que alguns cooperados estudam à noite, mas que, pelos menos, $50 \%$ são analfabetos e o restante dos cooperados possui apenas a 4a série.

A importância da economia social e solidária baseia-se também no fato de este setor estar fortemente relacionado com o desenvolvimento ecossocioeconômico. Laville (2015) e Laville, Young e Eynaud (2015) ressaltam que a economia social e solidária, um híbrido da economia de mercado e da economia pública, se preocupa com comunidades abandonadas e desempenha um papel fundamental no processo de desenvolvimento comunitário, por ser um setor de mão de obra intensiva, satisfazer as necessidades locais, reduzir as disparidades locais na prestação de serviços e permitir o acesso a bens/serviços e à oportunidades de trabalho. As entrevistas realizadas corroboram os autores citados anteriormente, pois os cooperados relatam que houve uma significativa melhora na qualidade de vida depois que começaram a trabalhar na cooperativa.

Cabe destacar que os barcos com os quais os cooperados operam são de propriedade individual e foram adaptados para o transporte de passageiros. Cada barqueiro tem um custo diferente e um recebimento distinto, conforme o tamanho do barco e o número de passageiros que atende; isto evita que os cooperados tenham prejuízo. Dessa forma, cada cooperado soma o total de venda de passagens daquele dia e recebe $20 \%$ desse valor para suas despesas com combustível. Os $80 \%$ restantes vão para a cooperativa que, após retirar $10 \%$, divide a sobra com todos os cooperados que trabalharam naquele dia. Essa forma de distribuição dos rendimentos está alinhada à perspectiva da economia social e solidária e à dimensão socioeconômica do DTS (IRION, 1997; SINGER, 2000).

A distribuição dos resultados da semana é feita no sábado, assim como a escala de trabalho da semana seguinte. A escala possibilita que os cooperados possam folgar nos dias em que se dedicam à pesca, uma vez que todos os cooperados aliam suas atividades na cooperativa com a pesca como forma de aumentar seus rendimentos (IRION, 1997; SINGER, 2000).

O Núcleo de Transporte da Prefeitura é responsável pelo aumento da passagem e pela fiscalização. A cooperativa atende um público de 450 passageiros/dia, em média. A principal dificuldade da cooperativa, segundo o presidente da cooperativa entrevistado, é a aplicação das normas estabelecidas no regulamento interno, pois muitos dos cooperados possuem laços de parentesco.

O presidente da associação entrevistado relatou que a cooperativa não possui recursos financeiros para ampliar o atual trajeto em direção a novos locais e assim criar novas linhas de transporte. Isso exigiria investimento para a compra de barcos e trapiches. Para esses novos investimentos a associação aguarda apoio da Prefeitura, que, segundo informações dos associados, já prometeu essa ampliação do trajeto dos barcos. Observa-se, assim, que a organização cooperativa se aproxima do ambiente empresarial, uma vez que engloba atividades voltadas para a solução de várias questões sociais, gerando benefícios econômicos reais para seus membros e partes interessadas (LAVILLE; YOUNG; EYNAUD, 2015; SACHS, 1993). 
A grande preocupação da cooperativa é a falta de apoio financeiro e capacitação técnica e profissional. Segundo a avaliação de um dos representantes da cooperativa, a ausência dos apoios impede que a cooperativa cresça. No caso da Prefeitura de Florianópolis, o apoio se refere apenas à construção de trapiches e pontos de barco. A cooperativa avalia que a presença de profissionais da área social, como assistentes sociais e psicólogos, junto a cooperativa, poderia facilitar a observância das normas internas e ajudar nas discussões em que não há consenso. Mais do que apoiadores, a cooperativa busca parceiros que se identifiquem com o grupo, com a economia solidária e seus valores, e com a extensão dela a outros grupos.

Embora os entrevistados relatem tais dificuldades, observa-se, a partir das práticas da cooperativa, a grande importância que a mesma tem tido para o incremento do turismo e para o desenvolvimento do território (TENÓRIO et al., 2018). Dessa forma, quanto à sustentabilidade cultural e social, destaca-se, por exemplo, a participação da cooperativa no ritual da procissão de culto religioso à Nossa Senhora dos Navegantes. Realizado desde 1968, o evento ocorre a partir do envolvimento da comunidade e dos barqueiros que hoje integram a cooperativa. Ademais, ainda referente à sustentabilidade cultural, a procissão, realizada todos os anos, é mobilizada pelos cooperados da Cooperativa e moradores locais. Além desses, mobiliza as pessoas que são devotas do culto, como os fiéis e os turistas. Todos participam da referida festa tradicional que é regada a iguarias açorianas, preparadas pelas famílias dos cooperados no salão da igreja. Esse cortejo em torno da Costa da Lagoa tornou-se uma grande atração turística para o território (FAGUNDES; ZORZELLA, 2012) e, segundo dados divulgados na mídia local, anualmente a cooperativa participa com 20 embarcações. Cerca de 300 pessoas integram o cortejo pelas ruas do bairro ou dentro dos barcos.

Destaca-se, também, quanto à sustentabilidade ecológica, outra atração que conta com a participação da cooperativa. Essa atração é o festival de outono de Florianópolis, que oferece diversas atrações culturais gratuitas: passeios de barcos, passeios nas trilhas, caminhada ecológica, shows na Praça da Lagoa, espetáculos teatrais, passeio de canoa havaiana, mutirão ecológico (limpeza da Praia do Saquinho), com saída do píer da cooperativa (SACHS, 1986; VIEIRA, 2006; SACHS, 2007). A atuação da cooperativa reforça a sustentabilidade ecológica por meio da habilidade na utilização da base de recursos potenciais existentes nos diversos ecossistemas, e combate o consumo supérfluo de mercadorias mediante a definição de regras para proteção ambiental, como acontece com as trilhas e o turismo. $\mathrm{O}$ aparato institucional assegura o cumprimento das normas, inclusive com apoio da comunidade local (SACHS, 1993).

Em termos de sustentabilidade ecológica e cultural, não se pode deixar de mencionar a contribuição da cooperativa para a preservação das trilhas da Costa da Lagoa, que foram tombadas com o Decreto Municipal no 247/86 e declaradas como Patrimônio Histórico e Cultural. A partir desse Decreto ficou tombada toda a encosta da margem Oeste da Lagoa da Conceição e o caminho da Costa da Lagoa, que se caracteriza por uma trilha que pode ser feita a pé, do início ao fim da Costa. Além do caminho da Costa, a vegetação e as edificações de interesse histórico e artístico também são protegidas por esse decreto (SACHS, 1986; VIEIRA, 2006; SACHS, 2007). 
Diante das atividades realizadas pela cooperativa pesquisada, verifica-se que os empreendimentos de economia social e solidária contribuem, no território pesquisado, para preservar a atividade tradicional da pesca artesanal, bem como para prestar serviço de interesse público, como é o caso do transporte de turistas e moradores. Assim, os serviços prestados pela cooperativa: i) ativam o turismo, apoiando os restaurantes e pousadas locais; ii) auxiliam os pescadores na geração de trabalho e renda para além da pesca; iii) promovem relações de reciprocidade e confiança no âmbito local; e iv) aproximam a população das paisagens e recursos naturais da Costa da Lagoa, um importante sítio natural da região da Grande Florianópolis - Santa Catarina.

Neste contexto, observa-se que a cooperativa de barcos impulsionou a formação de uma rede que surge no contexto das aglomerações territoriais com o potencial de sustentar o desenvolvimento e a competitividade do território - Costa da Lagoa.

\section{CONSIDERAÇÕES FINAIS}

Esse estudo teve como objetivo compreender de que maneira a Cooperativa de Barcos da Costa da Lagoa - um empreendimento de economia social e solidária - contribui para o fortalecimento, tanto do turismo quanto da cultura local, rumo ao desenvolvimento territorial sustentável. Após a realização da pesquisa, foram identificados alguns aspectos que compõem positivamente o quadro de possibilidades de organização e consolidação da economia social e solidária com vistas ao turismo na região, sendo eles: i) existência de tradições reconhecidas pelos moradores como sendo relevantes para a comunidade; ii) existência de algumas associações que geram mobilização, promovem aprendizagem coletiva e desenvolvem ações que extrapolam as atividades pesqueiras; iii) existência de relações de parentesco e amizade no âmbito comunitário, denotando a importância do sistema familiar para o desenvolvimento das atividades pesqueiras e para o incremento do turismo na região; iv) existência de uma rede informal de ajuda mútua comunitária aonde moradores realizam ações de solidariedade e cooperação, tanto em momentos de crise e de necessidade quanto no cotidiano da comunidade; $v$ ) prestação de serviços complementares, que geram atrativos para o turismo, como a existência de restaurantes, eventos folclóricos e venda de artesanato da região; e vi) atrativos relacionados à preservação do meio ambiente e do Patrimônio Histórico e Artístico.

Esses elementos têm favorecido o desenvolvimento do território, que pode se estruturar de forma comunitária e se fortalecer para atender à demanda do turismo local. Além disso, essa identidade, formada e reforçada por esses laços (capital social), compõe características que marcam o tipo de turismo realizado, bem como criam um contexto de sustentabilidade cultural (SACHS, 1993) que garante a manutenção da atividade desenvolvida bem como a transmissão geracional.

Por outro lado, alguns elementos foram identificados como enfraquecedores das ações coletivas na região pesquisada e, por isso, são pontos que podem ser desenvolvidos com a comunidade no sentido de aprimorar seu olhar e atuar junto ao poder público da cidade de Florianópolis. Os pontos para intervenção identificados foram: i) pouco investimento por parte do poder público, que poderia mobilizar mais recursos, como a modernização da frota de barcos; ii) pouca preocupação dos pescadores artesanais e de suas instituições com projetos de longo prazo, posto que a racionalidade 
do curto prazo é predominante; iii) carência de assessoria qualificada e de apoio técnico por parte de órgãos públicos e de organizações não governamentais; iv) falta de interação e/ou trabalho conjunto com outras cooperativas; e v) pouca ênfase da Cooperativa na formação, aprendizagem coletiva, treinamento e informação.

Este estudo constatou que a cooperativa analisada tem criado a possibilidade de atividades autogestionadas, nas quais as pessoas se encontram no centro do processo, desenvolvendo seus objetivos com base nos princípios de solidariedade, coletivismo e democracia. Trata-se de um espaço de integração social, construção de identidade e exercício da cidadania. Diante disso, deve-se considerar que o turismo, na Costa da Lagoa, tem-se constituído em alternativa possível para o aumento da renda das famílias, aliando a atividade da pesca com a do turismo e transporte.

Percebemos que a universidade, preservando suas características de pesquisa, extensão e ensino, pode cooperar com a construção da economia social e solidária intermédio de pesquisas e elaborações teóricas. No nosso entendimento, é fundamental que professores, estudantes e técnicos se envolvam na formação e na incubação de cooperativas. Acredita-se que este pode ser um espaço de aprendizagem, observação e reflexão sobre tal modo de produção (SINGER, 2002).

Outra sugestão de estudos e atividades de extensão é no sentido de compreender e intervir no desenvolvimento de uma visão técnico-administrativa para a cooperativa, uma vez que essa demonstrou dificuldades em assegurar sua viabilidade econômica, seu crescimento e sua sustentabilidade.

O trabalho identificou, por fim, que a economia solidária tem um papel fundamental na preservação das atividades e comunidades tradicionais, como é o caso da pesca artesanal e de eventos comunitários, como os religiosos. Faz-se necessário estudos futuros que reconheçam quais são as redes e parcerias e investimentos necessários para a continuidade das atividades que já existem na Costa da Lagoa, de forma a garantir o desenvolvimento territorial a longo prazo.

\section{REFERÊNCIAS}

ACl. Aliança Cooperativa Internacional. Guidance Notes to the Co-operative Principles. Available from: $\mathrm{http}$ ://ica.coop/en/media/library/the-guidance-notes-on-the-co-operative-principles. Cited: 10 maio 2016.

ANDRIGHI, F. F.; HOFFMANN, V. E. Redes e cooperação na destinação turística de Urubici/SC. Revista Turismo em Análise, USP, v. 21, n. 1, p. 149-164, 2010.

BAGNASCO, A. Desenvolvimento regional, sociedade local e economia difusa. In: URANI, A.; COCCO, G.; GALVÃO, A. P. (org.). Empresários e empregos nos novos territórios produtivos: o caso da terceira Itália. Rio de Janeiro: DP\&A, 1999. p. 33-44.

BECATTINI, G. Os distritos industriais na Itália. In: URAMI, A.; COCCO, G.; GALVÃO, A. P. (org.). Empresários e empregos nos novos territórios produtivos: o caso da terceira itália. Rio de Janeiro: P\&A, 1999. p. 45-58. BENKO, G. A recomposição dos espaços. Interações, Revista Internacional de Desenvolvimento Local, Campo Grande, v. 1, n. 2, p. 7-12, 2001.

BITTENCOURT, B. L. Políticas de desenvolvimento local sustentável e o terceiro setor: estudo de caso na região de Aveiro. 2014. Tese (Doutorado) - Universidade de Lisboa, Instituto Superior de Economia e Gestão, Lisboa, 2014.

BITTENCOURT, B. L.; RONCONI, L. F. A. Políticas de inovação e desenvolvimento: o caso da Bolsa de Terras. Rev. Adm. Pública, Rio de Janeiro, v. 50 n. 5, p. 795-817, 2016.

BUHALIS, D. Marketing the competitive destination of the future. Tourism management, v. 21, n. 1, p. 97$116,2000$. 
CARRIÈRE, J-P.; CAZELLA, A. Abordagem introdutória ao conceito de desenvolvimento territorial. Eisforia, v. 4, p. 23-47, dez. 2006.

CARY, P.; LAVILLE, J-L. L'économie solidaire: entre transformations institutionnelles et chantiers théoriques. Reveu Française de Socio-Économie, v. 1, n. 15, p. 23-37, 2015.

CESE. Comité Económico e Social Europeu. A economia social na União Europeia. Bruxelas: Cese, 2007.

COURLET, C.; SOULAGE, B. Industrie, territoires et politiques publiques. Paris: Editions L'Harmattan, 1994.

COURLET, C. Territoires et régions, les grands oubliés du developpement économique. Paris: L'Harmattan, 2001.

COURLET, C. Os sistemas produtivos localizados: da definição ao modelo. Eisforia: Desenvolvimento Territorial Sustentável: Conceitos, Experiências e Desafios Teórico-Metodológicos, Florianópolis: PPGAGR, v. 4, n. especial, dez. 2006.

DA LUZ, E. P. A.; MARTINS, P. Cultura náutica e patrimônio material: um olhar sobre a Costa da Lagoa, Ilha de Santa Catarina. Revista Brasileira de Estudos Urbanos e Regionais, v. 16, n. 2, p. 205-223, 2014.

FAGUNDES, J. P.; ZORZELLA, L. S. A teoria do desenvolvimento sustentável e a efetiva participação da COOPERCUC no desenvolvimento local. Desenvolvimento em Questão, v. 10, n. 20, p. 168-195, 2012.

FARIA, M. S. Autogestão, cooperativa, economia solidária: avatares do trabalho e do capital. 2005. Tese (Doutorado em Sociologia Política) - Universidade Federal de Santa Catarina, Florianópolis, 2005.

GRANOVETTER, M. S. The strength of weak ties. American journal of sociology, v. 78, n. 6, p. 1.360-1.380, 1973.

GRANOVETTER, M. Le marché autrement - les réseaux dans l'économie. Paris: Desclée de Brouwer, 2000. (Coll. Sociologie économique).

GUILLAUMON, S. Turismo em territórios de grande densidade religiosa. Organizações \& Sociedade, v. 19, n. 63, p. 679-696, 2012.

IBGE. Instituto Brasileiro de Geografia e Estatística. Estimativas populacionais para os municípios e para as Unidades da Federação brasileiros em 01.07.2015. 2015. Disponível em: http://www.ibge.gov.br/ home/estatistica/populacao/estimativa2015/. Acesso em: 1ㅇ maio 2016.

IORGULESCU, M-C.; RĂVAR, A. S. The Contribution of social enterprises to the development of tourism. The case of Romania. Procedia Economics and Finance, v. 32, p. 672-679, 2015.

IRION, J. E. Cooperativismo e economia social. São Paulo: Ed. STS, 1997.

LAVILLE, J-L. Changement social et économie solidaire: les événements dans le processus de recherche. Nouvelle revue de psychosociologie, v. 1, n. 19, p. 181-194, 2015.

LAVILLE, J-L.; YOUNG, D. R.; EYNAUD, P. (ed.). Civil society, the third sector and social enterprise: governance and democracy. New York: Routledge, 2015. p. 1-29.

MAPASBLOG. 2011. Disponível em: https://mapasblog.blogspot.com/2011/02/mapas-de-florianopolis-sc. html.

MINAYO, M. C. S. Ciência, técnica e arte: o desafio da pesquisa social. In: MINAYO, Maria Cecília de Souza (org.). Pesquisa social: teoria, método e criatividade. 11. ed. Petrópolis: Vozes, 1994. p. 69-89.

MENEZES, E C. O. Cooperativismo e desenvolvimento territorial sustentável: orientações estratégicas e alternativas de geração de trabalho e renda das comunidades pesqueiras da Grande Florianópolis - Santa Catarina. 2011. Relatório Pós-Doutorado (Pós-Doutorado em Administração) - Universidade Federal de Santa Catarina, Florianópolis: UFSC, 2011.

MENEZES, E. C. O.; RONCONI, L. F. A.; SERVA, M. R. Governança dos recursos de uso comum e desenvolvimento territorial sustentável: análise dos arranjos institucionais da pesca na Grande Florianópolis. Revista de Gestão Social e Ambiental, v. 10, n. 1, p. 22-40, 2016.

MENEZES, E. C. O.; VIEIRA, P. H. F. Aglomeração industrial, governança e meio ambiente: conceitos e premissas da abordagem do Desenvolvimento Territorial Sustentável. Desenvolvimento e Meio Ambiente, UFPR, v. 24, p. 101-118, 2011.

MTUR. Ministério do Turismo do Brasil. Dados e Fatos. Estudos, pesquisas e dados sobre o setor de turismo. Disponível em: www.turismo.gov.br. Acesso em: 1을 2016.

MTUR. Ministério do Turismo do Brasil. Plano nacional de turismo - 2018-2020: mais emprego e renda para o Brasil. Disponível em: www.turismo.gov.br. Acesso em: 3 ago. 2018.

NAMORADO, R. Para uma economia solidária - a partir do caso português. Revista Crítica de Ciências Sociais, Coimbra, n. 84, p. 65-80, mar. 2009.

PECQUEUR, B. A guinada territorial da economia global. Política \& Sociedade, Florianópolis, n. 14, p. 79105, abr. 2009. 
PECQUEUR, B. A guinada territorial da economia global. Eisforia: desenvolvimento territorial sustentável: conceitos, experiências e desafios teórico-metodológicos. PPGAGR, Florianópolis, v. 4, n. especial, dez. 2006.

RICHARDSON, R. J. et al. Pesquisa social: métodos e técnicas. São Paulo: Atlas, 1985.

RONCONI, L. F. A. Gestão social e economia solidária: desafios para o serviço social. 2003. Dissertação (Mestrado em Serviço Social) - Universidade Federal de Santa Catarina. Florianópolis, 2003.

RONCONI, L. F. A. Secretaria Nacional de Economia Solidária: uma experiência de governança pública. 2008. Tese (Doutorado em Sociologia Política) - Universidade Federal de Santa Catarina, Florianópolis, 2008.

RONCONI, L. F. A. A gestão pública da economia social e solidária em Portugal e no Brasil. Relatório Pós-Doutoral (Pós-Doutoramento em Sociologia Económica e das Organizações) - Instituto Superior de Economia e Gestão, Universidade Técnica de Lisboa, Lisboa: Iseg, 2012.

RONCONI, L. F. A.; FERREIRA, J. M. C. A Gestão pública da economia social em Portugal. In: SANTOS, Maria João; SEABRA, Fernando Miguel; JORGE, Fátima; COSTA, Fátima (orgs.). Responsabilidade social: na governação, nas empresas e nas organizações não empresariais. 1 ed. Coimbra: Almedina, 2014, v. 1, p. 5-335.

SACHS, I. Ecodesenvolvimento: crescer sem destruir. São Paulo: Vértice, 1986.

SACHS, I. Ecodesenvolvimento: 1972-1992. In: MAIMON, D. (org.). Ecologia e desenvolvimento. Rio de Janeiro: Aped, 1992. p. 7-11.

SACHS, I. Estratégias de transição para o século XXI: desenvolvimento e meio ambiente. São Paulo: Studio Nobel; Fundap, 1993.

SACHS, I. Ambiente e estilos de desenvolvimento. In: SACHS, I. (org.). Rumo à Ecossocioeconomia. Teoria e prática do desenvolvimento. São Paulo: Cortez, 2007. p. 54-76.

SEE. Social Economy Europe. Social economy in the EU. Available from: https://ec.europa.eu/growth/sectors/social-economy_en. Cited: 10 ago. 2017.

SENAES. Secretaria Nacional de Economia Solidária. Ministério de Trabalho e Emprego. Brasil, 2007. Disponível em: http://www.mtps.gov.br/ecosolidaria/secretaria-nacional-de-economia-solidaria/. Acesso em: 1 1 maio 2016.

SERAFIM, M. C. et al. Capital social na Costa da Lagoa: entre a confiança e a solidariedade. Encontro de Administração Pública e Governo. EnAPG, Salvador, 2012.

SEVERO, C. M. Pesca artesanal em Santa Catarina: evolução e diferenciação dos pescadores da Praia da Pinheira. 2008. Dissertação (Mestrado) - UFRGS, Programa de Pós-Graduação em Desenvolvimento Rural, Programa Interdisciplinar em Ciências Sociais, Porto Alegre, 2008.

SIMAENS, A. Strategic management in third sector organizations: an overview of the Portuguese social solidarity cooperatives. 2007. Dissertação (Mestrado) - ISCTE, Lisboa, 2007.

SINGER, P. Globalização e desemprego: diagnósticos e alternativas. 4. ed. São Paulo: Contexto, 2000.

SINGER, P. Introdução à economia solidária. São Paulo: Fundação Perseu Abramo, 2002.

SOCIAL ECONOMY EUROPE. Social economy. Available from: http://www.socialeconomy.eu.org/social-economy. Cited: 20 fev. 2017.

TENÓRIO, F. G. et al. Turismo e desenvolvimento sustentável: uma análise das atividades turísticas em uma comunidade pacificada do Rio de Janeiro. Desenvolvimento em Questão, ljuí: Ed. Unijuí, v. 16, n. 43, p. 422-452, 2018.

TRIVIÑOS, A. N. S. Introdução à pesquisa em ciências sociais. São Paulo: Atlas, 1987.

UNWTO. World Tourism Organization. Specialized agency of the United Nations. Why tourism. Available from: http://www.tourism4development2017.org/why-tourism/. Cited: 18 abr. 2017.

VIEIRA, P. V. Ecodesenvolvimento: desvelando novas formas de resistência no Antropoceno. In: SOUZA, Cristiane Mansur de Moraes; SAMPAIO, Carlos Alberto Cioce; ALVES, Alan Ripoll; ALCÂNTARA, Liliane Cristine Schlemer (org.). Novos talentos: processos de educação para o ecodesenvolvimento. Blumenau: Nova Letra Gráfica e Editora, 2016.

VIEIRA, P. F. Do desenvolvimento local ao ecodesenvolvimento territorial. R. Inter. Interdisc. INTERthesis, UFSC, v. 10, n. 2, p. 119-141, 2013.

VIEIRA, P. F. Rumo ao desenvolvimento territorial sustentável: esboço de roteiro metodológico participativo. Eisforia, UFSC, v. 4, n. especial, p. 249-310, 2006. 